\title{
O telejornalismo como lugar de referência e a função pedagógica
}

RESUMO

O objetivo deste artigo é propor algumas reflexões sobre o que denominamos de função pedagógica do telejornalismo. Entendemos que o noticiário televisivo através de operações/construções didáticas pode contribuir para que homens e mulheres possam compreender o mundo da vida, o cotidiano tenso e permeado por conflitos ao qual eles têm cada vez menos acesso. Para tanto partimos do pressuposto que o noticiário da televisão é um lugar de referência. Ou seja, ele nos mostra que o mundo existe, está presente na "telinha". O que os jornalistas fazem diariamente é "organizar o mundo" procurando torná-lo mais compreensível para homens e mulheres.

\section{PALAVRAS-CHAVE}

telejornalismo

lugar de referência

função didática

\section{ABSTRACT}

The aim of this article is to propose reflections about what we name TV news pedagogical function. We understand that the news on TV through didactical operations/constructions may contribute to the men and women's life world comprehension, composed by a thought day by day permeated by conflicts which they have much less access. Therefore we suppose that $T V$ news is a place of reference. It means, it shows us that the world exists and its on the TV screen. What the journalist do daily is "to organize the world" trying to show it in a more comprehensible way to the men and to the women.

\section{KEY WORDS}

to news

place of reference

pedagogical function
0 jornalismo, em particular o televisivo, é uma forma de conhecimento crítico que tem como preocupação interpretar a realidade social (Gomis, 1991), (Genro, 1987), (Meditsch, 1992), (Tuchmann, 1983). É resultado de uma atividade profissional de mediação vinculada a uma organização que se dedica basicamente a interpretar a realidade social e mediar os que fazem parte do "espetáculo mundano" e o público. Compartilhamos com a afirmação de Gomis (1991) e consideramos que a mídia não só transmite, mas prepara e apresenta uma realidade dentro das normas e das regras do campo jornalístico contribuindo dessa forma para a percepção do mundo da vida.

O objetivo deste artigo é propor algumas reflexões sobre a função pedagógica do telejornalismo, consideramos que o jornalismo televisivo contribui para a compreensão do mundo por homens e mulheres nas sociedades complexas (Melluci, 2001). Partimos do pressuposto que o noticiário da televisão é um lugar de referência (Vizeu; Correia, 2007). O cotidiano é organizado dentro das regras e normas do campo jornalístico que funciona como um lugar de mediação entre os acontecimentos e as notícias buscando tornar mais acessível o entorno que nos cerca.

Quando assistimos à televisão adotamos o que Schütz (2003) denominou de atitude natural. Como observou o autor, no dia adotamos uma postura de suspensão da dúvida em relação ao cotidiano. Ou seja, cremos que as coisas são como estão evidenciadas na realidade. Isso não pode nos levar a raciocínio contrário, que as pessoas não têm dúvidas com relação ao que observam e percebem diariamente. Como uma forma de sobrevivência, elas suspendem a dúvida. Acreditamos que a televisão na sociedade contemporânea cumpre essa a função de reforçar que a realidade existe e que não estamos sozinhos no mundo.

Para procurarmos dar conta desta caminhada o artigo está dividido em quatro momentos: telejornalismo como um lugar de referência, o conhecimento do jornalismo, a função pedagógica do jornalismo e a operação/construção didática jornalística. Essa divisão tem basicamente uma preocupação didática porque esses momentos não são estanques; pelo contrário, estão imbricados e acontecem de uma forma dinâmica no complexo processo de produção da notícia.

Em outro trabalho já abordamos de uma forma exaustiva o telejornalismo como lugar de referência (Vizeu; Correia, 2007). Quando propomos esse conceito temos como hipótese que o jornalismo televisivo representa um "lugar" para os brasileiros, muito semelhante ao da família, dos amigos, da escola, da religião e do consumo. Assistimos à televisão e vemos 
o mundo, ele está, ele nos vê.

Como explica Giddens (2003), as rotinas diárias desempenham um papel central na sociedade. Por isso defende que a confiança na continuidade do mundo objetivo e no tecido da atividade social depende de certas conexões especificáveis entre os indivíduos e os contextos dos quais se movimenta no cotidiano.

A seguridade ontológica mostra a fé que a maior parte dos seres humanos tem na continuidade de sua identidade própria e na "estabilidade" dos meios circundantes de ação social e material. A crença na fidelidade das pessoas e das coisas, essencial a noção de confiança, é fundamental para os sentimentos de segurança ontológica.

Os trabalhos no campo da recepção no Brasil apontam nessa perspectiva da televisão como um lugar de referência. Num estudo sobre a recepção entre jovens universitários cariocas, Travancas (2007, p. 88):

Eu me perguntava, no início deste trabalho, se os jovens assistiam ao Jornal Nacional e o que eu faria durante a pesquisa, descobrisse que eles não vêem. Mas, aos poucos, não só fui confirmando o quanto o JN é uma referência também para eles, como é fonte de sentimos os mais variados, que vão do amor ao ódio, jamais da indiferença.

Travancas (2007, p. 95-96), explica que na pesquisa constatou que o JN, como parte de um sistema mais amplo de comunicação, pode afetar e influenciar o conjunto de informações e conhecimentos que esses jovens adquirem, assim como seus projetos pessoais. Ou seja, o telejornal é um lugar de referência para esses jovens num mundo cada vez mais conturbado. Como acrescenta a autora: "Não é à toa que alguns comentavam que, embora o jornal mostrasse tragédias e notícias negativas, assistir ele dava uma sensação de tranqüilidade. E comentavam que viam o JN também para relaxar de suas rotinas estressantes e corridas de uma grande metrópole".

\section{Consideramos que a mídia não só transmite, mas prepara e apresenta uma realidade dentro das normas e das regras do campo jornalístico contribuindo dessa forma para a percepção do mundo da vida}

No mundo do trabalho, a televisão também se coloca como um lugar de referência mesmo diante do olhar crítico dos trabalhadores. Num estudo de recepção, sobre o mundo do trabalho como mediação da comunicação, Paulino (2001) observou que o telejornal se destaca como a programação predileta do trabalhador. Ele se sente informado sobre o que acontece na sua cidade, no seu País e no mundo através do noticiário televisivo.

Como esclarece a autora, o anseio de estar bem informado extrapola o horizonte imediato, da realidade mais próxima. $\mathrm{Na}$ investigação ela identificou que para os trabalhadores pesquisados, estar bem informado significa saber das transformações que vão pelo mundo e pelo País. A experiência deles mostra que essas mudanças interferem na vida pessoal e no mundo do trabalho.

Esse lugar de referência da televisão, em particular do telejornalismo, como um espaço também educativo, diria pedagógico, também foi registrado na pesquisa realizada por Cogo e Gomes (2001) sobre televisão, escola e juventude:

Embora contraditórias, as diferentes posturas diante da TV explicitadas pelos entrevistados revelam que pais e educadores, a exemplo do que foi observado entre os adolescentes, reconhecem o papel educativo exercido pela televisão. Esse reconhecimento tornase evidente mesmo quando questionam a exagerada liberalidade que esse papel é exercido e o próprio risco que a autoridade dos pais e educadores e ao processo de reafirmação de determinados valores no processo educativo dos adolescentes (2001, p. 94).

Se a televisão ocupa este lugar de referência e contribui para que homens e mulheres possam compreender o mundo que os cerca, não é uma ousadia afirmar que o telejornalismo é uma forma de conhecimento. Agora, que forma de conhecimento? É uma forma de conhecimento crítico que tem como preocupação interpretar a realidade social (Gomis, 1991), (Genro, 1987), (Meditsch, 1992), (Tuchmann, 1983).

É resultado de uma atividade profissional de mediação vinculada a uma organização que se dedica basicamente a interpretar a realidade social e mediar os que fazem parte do "espetáculo mundano" e o público. Compartilhamos com a afirmação de Gomis (1991) e consideramos que a mídia não só transmite, mas prepara e apresenta uma realidade dentro das normas e das regras do campo jornalístico contribuindo dessa forma para a percepção do mundo da vida.

\section{Telejornalismo: o contexto é a práxis}

Como esse conhecimento opera? Entendemos que a contribuição de Freire (2005) pode ajudar-nos para tentar explicar esse processo. Consideramos que ele funciona ao longo de todo o processo de produção 
da notícia desde a apuração até chegar à audiência comunicativa, num processo circular, numa semiose infinita.

O contexto teórico do conhecimento do Jornalismo é o contexto da práxis. O jornalismo precisa "molharse" pela realidade. Ou seja, não há contexto teórico verdadeiro a não ser na união dialética com a prática, com o contexto concreto. No contexto teórico buscamos "tomar distância" dos fatos; no prático, no concreto somos sujeitos e objetos em relação ao objeto (Freire, 1987).

Nas práticas diárias de produção da notícia é esse procedimento que os jornalistas adotam o tempo todo, muitas vezes de forma inconsciente. No "contexto teórico" de elaboração da informação, o repórter e/ou o redator assumem o papel de sujeitos cognoscentes da relação sujeito-objeto que se dá no contexto concreto para, voltando a este, melhor atuar como sujeitos em relação ao objeto. Consideramos que essa relação teoria/prática faz parte do método de apuração de uma matéria, de edição e de apresentação. O método jornalístico tem que ser trabalhado com rigor (Cornu, 1999).

As informações essenciais não podem ser suprimidas. As notícias devem trazer detalhes básicos para que possam ser compreendidas. As várias faces de um acontecimento devem ser apresentadas. $\mathrm{Na}$ construção da notícia é preciso estar sempre atento para que aspectos da realidade não sejam ocultados nem silenciados Os textos têm que buscar uma objetividade possível, tomando-se cuidado em não alterar textos e documentos.

A investigação é da essência do jornalismo porque diminui a possibilidade do erro e do equívoco. Caso isso ocorra, ainda dentro das práticas jornalísticas, fazse necessário retificar a informação publicada que se revela inexata. No entanto, uma das tarefas centrais do rigor do método, do conhecimento do Jornalismo, é evitar a ambigüidade na informação. Outro aspecto importante no atual processo de produção da notícia é sob a ditadura da audiência, da concorrência, precarizar a qualidade da informação noticiosa (Cornu, 1999).

Por isso, como alerta Freire (1987) - e é importante nas práticas sociais do jornalismo - precisamos ir além da mera captação dos fatos buscando não só a interdependência entre eles, mas também o que há entre as parcialidades constitutivas da totalidade de cada um. Nesse sentido, o jornalismo necessita estabelecer uma vigilância constante sobre a sua própria atividade.

Ainda dentro da perspectiva de Freire (1997) consideramos que a comparação que o autor faz entre a ingenuidade e a criticidade pode contribuir para entendermos o Conhecimento do Jornalismo - que trata dos acontecimentos do mundo, dos diversos saberes, dos campos da experiência e do cotidiano. $\mathrm{O}$ autor esclarece que não há diferença e nem distância entre a ingenuidade e a criticidade. Para Freire, entre o saber da pura experiência e dos procedimentos metodicamente rigorosos ocorre uma superação.

Freire (1997) argumenta que não acontece uma ruptura porque a curiosidade ingênua, sem deixar de ser curiosidade, continuando a ser curiosidade se criticiza. Continuando a explicação diz que ao se criticizar, tornando-se curiosidade epistemológica, metodicamente "rigorizando-se" na sua aproximação ao objeto, conota seus achados de maior exatidão. A curiosidade metodicamente rigorosa do método cognoscível se torna curiosidade epistemológica, mudando de qualidade, mas não na essência.

É dentro desse quadro que opera o conhecimento do jornalismo. Na produção da notícia o jornalista trabalha constantemente dentro dessa perspectiva de superação. Não é permitido ao jornalista que seja ingênuo na cobertura dos fatos. A tomada de consciência (Freire, 2003) é o ponto de partida da sua atividade. Como é possível dar conta da cobertura dos acontecimentos, da mediação entre eles e a sociedade, se antes de construir a informação não conheço o objeto? É tomando consciência dele que me dou conta do objeto, que é conhecido por mim.

A eficácia da atividade jornalística e o Conhecimento do Jornalismo estão intimamente ligados ao que Freire (1995) colocava como a capacidade de abrir a "alma" da cultura, de aprender a racionalidade da experiência por meio de caminhos múltiplos, deixando-se "molhar, ensopar" das águas culturais e históricas dos indivíduos envolvidos na experiência. É dimensão crítica do conhecimento jornalístico, num imbricamento entre teoria e prática. Há dois aspectos importantes do método Paulo Freire para pensarmos o Jornalismo não só do ponto de vista metodológico, mas como uma forma de conhecimento: a problematização e o diálogo.

\section{0 que os jornalistas fazem diariamente é "organizar o mundo" procurando torná-lo mais compreensível. Por isso, há uma preocupação pedagógica no jornalismo que se legitima como o lugar de "poder mostrar", de "poder dizer" e de "poder analisar"}


Ao abordar o papel da problematização na Educação na produção do conhecimento, Freire (1987) defende que o conhecimento científico e a elaboração de um pensamento rigoroso não podem prescindir de sua matriz problematizadora, a apreensão de ambos não pode prescindir igualmente da problematização, deve ser feita em torno de o próprio saber que o educando deve incorporar.

Como na Educação, acreditamos que a problematização também ocupa um papel central no Jornalismo. Não é possível se falar em conhecimento do jornalismo sem uma problematização constante das práticas jornalísticas, na função do Jornalismo de informar. Outro aspecto importante é a também centralidade do diálogo nos processos jornalísticos de construção do real, o fazer jornalístico é um "estar em diálogo".

\section{0 telejornalismo e a "organização do mundo"}

O que os jornalistas fazem diariamente é "organizar o mundo" procurando torná-lo mais compreensível. Por isso, há uma preocupação pedagógica no jornalismo que se legitima como o lugar de "poder mostrar", de "poder dizer" e de "poder analisar". O jornalismo se auto-referencia como um lugar de mediação, de desegredização, de revelação da verdade e orientação de homens e mulheres na contemporaneidade.

Tuchmann (1980) afirma que o enquadramento das notícias organiza a realidade cotidiana e é parte importante dessa por causa do caráter público que é uma característica essencial da notícia. Complementa afirmando que a notícia não só define, redefine, constitui e reconstitui significados sociais; mas também define e redefine, constitui e reconstitui maneiras de fazer coisas: os processos existentes e as instituições. E a função pedagógica ocupa um papel central nesse processo.

\section{Telejornalismo: a função pedagógica}

As notícias devem ter a preocupação de contribuir para o entendimento do mundo da vida. Verón (1983) vê o jornalista como um "enunciador pedagógico", que pré-ordena o universo do discurso visando o leitor, que procura orientar, responder-lhe às questões, em suma informar, sempre guardando uma distância do objetivo dele.

Essa função pedagógica é trabalhada diariamente pelos jornalistas na redação através de uma operação/ construção que denominamos de didática (Vizeu, 2005), (Vizeu; Correia, 2006). É resultado de uma série de enquadramentos culturais, das práticas sociais, da cultura profissional, dos constrangimentos organizacionais e do campo da linguagem que os jornalistas mobilizam para produzirem notícias.

Vilches (1989) observa que não se pode esquecer queo telejornal estabelece com o espectador (audiência) uma relação pedagógica, pois ensina como se portar diante do texto televisivo, com que atitude comunicativa e em que condições devem aprender as características do gênero. Ou seja, operando de uma forma didática a notícia faz uma mediação entre os diversos campos de conhecimento e o público.

Vejamos um exemplo para deixar mais clara essa preocupação didática. Ao se referir a um exame médico que não é conhecido pela maioria da audiência, o editor, de uma maneira geral, vai ter a preocupação, ao redigir o texto para o locutor, explicar para que serve aquele determinado exame:

Loc: Os médicos ficaram surpresos com o resultado do exame que registra a atividade linfocitária de um paciente com AIDS. O exame é feito para medir a capacidade de defesa imunológica de uma pessoa.

Tomamos como exemplo alguns manuais. É nessa perspectiva que tratamos do pioneiro dos manuais de redação e a sua relação com os atuais. É importante ressaltar que só trabalharemos com os manuais de jornais impressos.

O texto jornalístico é um espaço habitado, um universo em movimento: "ler" é por em movimento esse universo, aceitando-o ou recusando-o, indo à direita ou à esquerda, investindo mais ou menos esforço, fingindo escutar ou escutando.

Os jornalistas, de uma maneira geral, têm uma preocupação "didática" com relação à audiência. Isso é trabalhado desde os tempos da universidade até o dia-a-dia da redação. No que diz respeito ao mundo acadêmico, o livro de Paternostro: "O Texto na TV: Manual de Telejornalismo", adotado pela maioria dos cursos de jornalismo do Brasil, é um exemplo disso.

No capítulo que trata do texto coloquial, a autora diz que a tevê tem a obrigação de respeitar o telespectador e transmitir a informação em uma linguagem coloquial e correta. Ela explica que quem assiste ao telejornal só ouve o texto uma vez, por isso deve ser capaz de captálo, processá-lo e retê-lo instantaneamente. Não há uma segunda chance.

Se o telespectador se desligar, não há desculpas: o erro foi nosso. Quanto mais as palavras (ou o texto como um todo) forem 'familiares' ao telespectador, maior será o grau de comunicação. As palavras e as estruturas das frases devem estar o mais próximo possível de uma conversa. Devemos usar palavras simples e fortes, elegantes e bonitas, apropriadas ao significado e à circunstância da história que queremos contar (Paternostro, 1999, p. 78-85).

A autora, experiente profissional da Rede Globo de Televisão, onde trabalhou como editora, editora-chefe de um jornal de Rede e chefe de redação da Globo News, canal de notícias da tevê paga, hoje na função de assessora da direção da empresa, sabe bem do que está falando. Atualmente ela é a responsável pela Gerência de Desenvolvimento de Jornalistas da Globo. 
O "Manual de Telejornalismo da Rede Globo" assume um "ar professoral" ao explicar como o telespectador, a audiência deve ser tratada:

Um dos grandes desafios do telejornalismo é a 'tradução' de informações técnicas, a apresentação de pacotes econômicos, a decifração de termos financeiros, etc. Tanto o repórter - na hora de colher as informações - como o redator, na hora de escrever o off, a cabeça da matéria deve ser humilde o suficiente para perguntar, pesquisar e simplificar [...] É preferível sermos tachados de professorais por uma elite de escolarização a não sermos entendidos por uma massa enorme de telespectadores comuns (Manual Globo de Telejornalismo, 1986, p.23-24).

Dezesseis anos depois, o "Novo Manual de Telejornalismo da Rede Globo" (2001) não foge muito das recomendações do primeiro na sua preocupação com a audiência. Segundo o manual, toda informação deve ser precisa, cada imagem ou cada palavra escolhida criteriosamente, sob pena de distorcer os fatos e confundir o telespectador:

A nossa honestidade e ética podem ser involuntariamente comprometidas por imprecisões que levem ao telespectador a nos confundir com praticantes de um jornalismo tendencioso e irresponsável [...] (Novo Manual Globo de Telejornalismo, no prelo).

\section{A operação/construção didática do jornalismo}

Esses comentários que dizem respeito aos telejornais são aplicados de uma maneira geral a todo o campo jornalístico porque é da essência do campo explicar a audiência. Para deixarmos mais claro o que é operação/ construção didática tomamos um exemplo da pesquisa que realizamos sobre a "audiência presumida", no ano de 2000, num telejornal regional, o ESTV2 ${ }^{a} E D$, da afiliada da Rede Globo no Espírito, que vai ao ar às $18 \mathrm{~h} 45 \mathrm{~min}$, de segunda a sábado, observamos que nas suas práticas diárias o jornalista, na produção das notícias, se coloca como um "professor" a explicar a audiência, idealizada e presentificada nos textos como alguém que não sabe, determinados fatos. Vejamos dois exemplos que trabalhamos na nossa pesquisa. Os dois textos são aberturas de matérias de telvisão. $\mathrm{Ou}$ seja, é a parte que cabe ao locutor ou locutores lerem para introduzir a reportagem.

\section{VT - farmácias/genéricos 16/06/2000 ESTV2ªD}

(E1) Loc./apres.:

MAIS UM INSTRUMENTO A

FAVOR DA SAÚDE DO

CONSUMIDOR. / A PARTIR DE

AMANHÃ, A FARMÁCIA QUE

NÃO TIVER A LISTA DE
GENÉRICOS À MOSTRA VAI

SER MULTADA. / HOJE,

MUITAS DELAS JÁ ESTAVAM

CUMPRINDO A

DETERMINAÇÃO. / MAS O

CONSUMIDOR AINDA

CONTINUA ENCONTRANDO UMA

DIFICULDADE: ENCONTRAR O

GENÉRICO DESEJADO. / / /

/ / / / / / RODA VT / / / / / / /

No texto, o jornalista mostra que há mais um instrumento a favor da saúde doconsumidor. A situação permite inferir que já existiam outros instrumentos que beneficiavam o consumidor. Além disso, ainda no enunciado, ao utilizar "a partir de amanhã", cuidemse as farmácias, quem não tiver remédios genéricos nas prateleiras vai ser multado. No entanto, utilizando-se de uma estratégia argumentativa, contrapondo o "hoje ao amanhã" o jornalista diz que muitas delas não possuíam os genéricos.

$\mathrm{O}$ argumento é reforçado no enunciado com a ressalva do "mas" com a ênfase do "ainda", indicando que não está sendo fácil para os consumidores comprarem os genéricos nas farmácias porque eles não são encontrados. Essas orientações para o leitor estão recomendadas nos manuais de redação. No texto que segue também podemos observar essa preocupação didática do jornalismo.

\section{NS- UFES/vestibular 29/06/2000}

Loc./apres.

NOVIDADES NO VESTIBULAR

2001 DA UFES -

UNIVERSIDADE FEDERAL DO

ESPÍRITO SANTO. / DEVERÃO

SER OFERECIDAS 2 MIL 715

VAGAS. / QUARENTA A MAIS

QUE NO VESTIBULAR DESTE

ANO. / UM NÚMERO QUE AINDA

PODE MUDAR. / OS

DEPARTAMENTOS TÊM ATÉ O

DIA SETE DE JULHO PARA

ENVIAR NOVAS

PROPOSTAS. / ESTÁ DEFINIDO

QUE O NÚMERO DE CURSOS

CONTINUA O MESMO: 49. / UM

DELES MUDOU DE

NOME. / EDUCAÇÃO ARTÍSTICA

PASSA PARA ARTES VISUAIS

E AUMENTA O NÚMERO DE

VAGAS. / SOBE DE 30 PRA

60. / NOVIDADE TAMBÉM NO

CURSO DE LETRAS. / INGLÊS,

QUE GANHOU MAIS 10 VAGAS,

PASSANDO DE 40 PARA 50. /

AS INSCRIÇÕES PODERÃO SER 
FEITAS NO PERÍODO DE 16

DE AGOSTO A PRIMEIRO DE

SETEMBRO. / AS PROVAS

ACONTECEM EM NOVEMBRO. / / /

No texto jornalista também recorre à mesma estratégia da notícia anterior. Ao dar informações sobre as novidades do vestibular apresenta muitos detalhes sobre o assunto que poderiam ser obtidos pelo candidato no momento da inscrição no vestibular. $\mathrm{O}$ "tamanho" do mesmo até supera o padrão dos textos do telejornal, em torno de 15 linhas.

O jornalista "aciona" o operador argumentativo "mais" para informar aos candidatos que o número de vagas aumentou em relação ao ano de 2000 e que a oferta pode ser maior como indica o operador "ainda". Os estudantes têm que ficar à espera porque, como aponta operador, "até" o dia sete de julho é o prazo limite para que os departamentos enviem suas propostas. Ao final utiliza "também" e "mais", procurando reforçar o argumento da importância das novidades no vestibular para os candidatos: novidade no Curso de Letras também, ele ganhou mais dez vagas.

\section{VT- Morro do Macaco 17/05/2000}

(E21) Loc./apres. :

AGORA É PRA VALER. /

QUARENTA FAMÍLIAS VÃO

TER QUE DEIXAR AS CASAS

NO MORRO DO MACACO, EM

VITÓRIA. / ELAS OCUPAM

ÁREAS DE PRESERVAÇÃO./ A

PREFEITURA DEU O

ULTIMATO AOS

MORADORES. / / /

/ / / / / / RODA VT / / / / / / /

Nesta notícia, de uma forma didática, o jornalista procura explicar a audiência comunicativa o despejo de moradores de uma área de ocupação. Em primeiro lugar, procura explica de uma forma implícita que a Prefeitura não vai mais negociar, trata-se agora de um ultimato com base na lei. O esclarecimento, a explicação didática para a desocupação é de que áreas de preservação não podem ser habitadas. Ou seja, de uma maneira simples e direta a audiência é informada de que existe uma legislação que preserva essas áreas.

\section{- VT- delegacia PF/ Cachoe 11/07/2000}

(E24) Loc./apres. :

TIRAR PASSAPORTE NO SUL

DO ESTADO FICOU MAIS

FÁCIL E RÁPIDO. / NA

SEMANA PASSADA, FOI
INAUGURADA, EM CACHOEIRO,

A PRIMEIRA DELEGACIA DA

POLÍCIA FEDERAL NO

INTERIOR. / / /

/ / / / / / RODA VT / / / / / / /

A matéria pode acima pode ser enquadra no que hoje se denomina de matéria de serviço. Ou seja, uma notícia que procura orientar a comunidade sobre os serviços a disposição dela. O texto procura mostrar que se já era fácil e rápido tirar o passaporte antes, agora ficou ainda mais fácil. As pessoas agora não vão mais precisar se dirigir a Vitória, capital do Espírito Santo, porque foi inaugurada uma delegacia no interior do Estado. Isso vai facilitar aqueles à vida daqueles que querem viajar e precisavam perder um dia ou dois na capital para fazerem seus passaportes.

\section{VT- flagrante/ estradas 16/08/2000}

(E25) Loc./apres. :

A IMPRUDÊNCIA NAS

ESTRADAS. / NESTA

SEMANA, EM APENAS DOIS

DIAS, SETE PESSOAS

MORRERAM. / EM TODOS OS

ACIDENTES, CAMINHÕES

ENVOLVIDOS. / OS NÚMEROS

DA POLÍCIA RODOVIÁRIA

FEDERAL MOSTRAM QUE A

MAIORIA OCORRE NA BR-101

SUL. / DE JANEIRO ATÉ

HOJE, FORAM 59 MORTES. / / /

/ / / / / / RODA VT / / / / / / /

Ao mobilizar o advérbio "apenas" o texto torna mais forte o argumento da imprudência nas estradas já que, em dois dias, sete pessoas morreram. As demais operações/construções: "todos", "maioria" e "hoje" contribuem no sentido de chamar atenção para o argumento principal: imprudências nas estradas. Identificamos ainda que, a notícia começa com uma frase sem verbo: A imprudência nas estradas. Tal estratégia aponta para uma verdade geral que exclui a forma verbal responsável pela particularização, buscando com isso chamar a atenção para o fato de que todos somos responsáveis pela segurança nas nossas rodovias.

\section{Em (conclusão)}

Nos exemplos acima nos detivemos basicamente nos textos. No entanto, texto e imagem funcionam de uma forma imbricada na televisão. Nos processos de edição, que não trabalhamos aqui, os jornalistas procuram mobilizar vários recursos de enquadramento, planos, cortes de edição, uso de arquivo do Departamento 
de Jornalismo, animações gráficas, trabalhos de pósprodução para possibilitar que a reportagem seja entendida pela audiência.

Ao final deste trabalho entendemos que ainda há muito a pesquisar sobre a função didática do telejornalismo, ainda mais levando em conta o lugar de referência que ele ocupa na sociedade brasileira. É, sem dúvida, a primeira forma de informação e de conhecimento da maioria da população brasileira sobre o mundo que a cerca. Com certeza, e isso merece mais estudos, é precisamos analisar e vermos como trabalhar o telejornalismo no sentido de contribuir para que as pessoas possam conhecer mais o mundo que as cerca e a partir disso viverem com mais tranqüilidade no mundo da vida. Esse é um desafio que se coloca para todos nós pesquisadores do campo do jornalismo e que procurei contribuir com algumas reflexões procurando motivar novas investigações $\square$ FAMEcos

\section{REFERÊNCIAS}

COGO, Denise e GOMES, Pedro Gilberto. Televisão, escola e juventude. Porto Alegre: Mediação, 2001.

CORNU. Daniel. Jornalismo e verdade. Lisboa: Piaget, 1999.

FAUSTO NETO, Antonio. Mortes em derrapagem: os casos Corona e Cazuza no discurso da comunicação de massa. Rio de Janeiro: Rio Fundo, 1991.

FREIRE, Paulo. Cartas a Cristina. Bauru: Unesp, 2003.

FREIRE, Paulo. Pedagogia da autonomia. Rio de Janeiro: Paz e Terra, 1997.

FREIRE. Paulo. Educação na cidade. São Paulo: Cortez, 1995.

FREIRE, Paulo. Ação cultura para a liberdade e outros escritos. Rio de Janeiro: Paz e Terra, 1987.

GIDDENS, Anthony. A constituição da sociedade. São Paulo: Martins Fontes, 2003.

GOMIS, Lorenzo. Teoria del periodismo: cómo se forma el presente. México: Paidós, 1991.

MANUAL GLOBO DE TELEJORNALISMO. Rio de Janeiro: Rede Globo, 1986.

MEDITSCH, Eduardo. O conhecimento do jornalismo. Florianópolis: EDUFSC, 1992.
MELUCCI, Alberto. A invenção do presente: movimento sociais nas sociedades complexas. Petrópolis: Vozes, 2001.

NOVO MANUAL GLOBO DE TELEJORNALISMO. Rio de Janeiro: Globo [2001?]. No prelo.

PATERNOSTRO, Vera I. O texto na tv: manual de telejornalismo. Rio de Janeiro: Campus, 1999.

PAULINO, Roseli. Comunicação e trabalho: estudo de recepção - o mundo do trabalho como mediação do mundo da comunicação. São Paulo: Roseli Fígaro/Fapes, 2001.

TRAVANCAS, Isabel. Juventude e televisão. Rio de Janeiro: FGV, 2007.

TUCHMANN, Gaye. La producción de la noticia: estudo sobre la construcción de la realidad. Barcelona: Gili, 1983.

VERÓN, Eliseo. Il est là, je le vois, il me parle. Revue Communications. N $^{\circ}$ 38. Paris: Seuil, p. 99-120, 1983.

VILCHES, Lorenzo. Manipulación de la información televisiva. Barcelona: Paidós, 1989.

VIZEU, Alfredo. O telejornalismo como lugar de referência a redução da complexidade nas sociedades contemporâneas. Encontro Nacional de Pesquisadores em Jornalismo, 6, 2008, São Paulo. Programação: a construção do campo do jornalismo no Brasil. São Paulo: SBPJor, p. 47, 2008.

VIZEU, Alfredo, CORREIA, João Carlos. A construção do real no telejornalismo: do lugar de segurança ao lugar de referência. In: VIZEU, Alfredo. A sociedade do telejornalismo. Petrópolis: Vozes, 2007. No prelo.

VIZEU, Alfredo. O lado oculto do telejornalismo. Florianópolis: Editora Calandra, 2005.

WOLF, Mauro . Teorias da comunicação. Lisboa: Presença, 1994. 